\title{
Characterization of stanniocalcin 1 binding and signaling in gill cells of Japanese eels
}

\author{
J Gu, A Y S Law, B H Y Yeung and Chris K C Wong
}

Department of Biology, Croucher Institute for Environmental Sciences, Hong Kong Baptist University, Kowloon Tong, Hong Kong, People's Republic of China

Correspondence should be addressed to C K C Wong Email ckcwong@hkbu.edu.hk

\begin{abstract}
Stanniocalcin 1 (STC1) is a hypocalcemic hormone that is known to play an important role in calcium metabolism in teleost fish. An increase in blood $\mathrm{Ca}^{2+}$ levels stimulates its synthesis and release. The biological action of STC1 inhibits gill $\mathrm{Ca}^{2+}$ transport (GCAT), but we as yet have no clear understanding of how STC1 inhibits GCAT. In the present study, we characterized the binding, signaling, and action of STC1 on gill cells. Treatment of gill cell cultures with the extracts of corpuscles of Stannius or recombinant STC1 proteins (STC1-V5) led to an increase in cytosolic cAMP levels. Using in situ ligand-binding assays, we demonstrated that STC1-V5 binds to both lamellar and inter-lamellar regions of gill sections. The binding sites were significantly increased in gill sections obtained from fish adapted to high- $\mathrm{Ca}^{2+}(2 \mathrm{mM})$ freshwater (FW) as compared with those from fish adapted to low-Ca ${ }^{2+}$ $(0.2 \mathrm{mM}) \mathrm{FW}$. Receptor-binding assays illustrated specific binding of STC1-alkaline phosphatase to plasma membrane $\left(K_{d}\right.$ of $\left.0.36 \mathrm{nM}\right)$, mitochondria $\left(K_{d}\right.$ of $\left.0.41 \mathrm{nM}\right)$, and nuclear $\left(K_{\mathrm{d}}\right.$ of $\left.0.71 \mathrm{nM}\right)$ preparations from gill cells. STC1 binding capacity was significantly greater in the plasma membrane preparations of gills obtained from fish adapted to high$\mathrm{Ca}^{2+}$ FW. Using isolated pavement cells and mitochondria-rich cells in CAMP assays, we obtained results indicating that both cell types responded to STC1. To illustrate the biological action of STC1, we conducted $\mathrm{Ca}^{2+}$ imaging experiments to demonstrate the effects of STC1 on thapsigargin-induced elevation of cytosolic $\mathrm{Ca}^{2+}$. Our results indicated that STC1 exerted its inhibitory action via a CAMP pathway to lower intracellular $\mathrm{Ca}^{2+}$ levels. Intriguingly, we were able to block the action of STC1 using an inhibitor, NS-398, of cyclooxygenase-2 (COX-2), which is known to stimulate the activity of sarcoplasmic and endoplasmic reticulum $\mathrm{Ca}^{2+}$-ATPase (SERCA). A follow-up experiment in which gill cells were incubated with STC1 revealed a downregulation of the epithelial $\mathrm{Ca}^{2+}$ channel (ecacl) but an upregulation of cox-2 expression. The $\mathrm{ECaCl}$ is a gatekeeper for $\mathrm{Ca}^{2+}$ entry, whereas $\mathrm{COX}-2$ mediates an activation of SERCA. Taking these results together, the present study is, to our knowledge, the first to provide evidence of STC1 binding and signaling as well as the first to decipher the mechanism of the effect of STC1 on fish gills.
\end{abstract}

\section{Key Words}

- calcium signaling

- fish

- gene expression

- hormone receptors
Journal of Molecular Endocrinology (2015) 54, 305-314
(C) 2015 Society for Endocrinology Printed in Great Britain
Published by Bioscientifica Ltd. 


\section{Introduction}

The fish gill is a multifunctional transport epithelium that simultaneously participates in an assortment of ion and molecule transport activities, including the transport of respiratory gases, universal osmolytes, nitrogenous waste, and water (Evans et al. 2005). The gill is critical to the regulation of ionic and osmotic homeostasis in fish and thus plays a large role in osmotic adaptability. A number of key hormones (growth hormone, cortisol, prolactin, natriuretic peptides, and stanniocalcin 1 (STC1)) have been identified that are essential in coordinating gill activity. Over the past decade, a considerable number of studies have investigated how ion-osmoregulatory function associates with changes in plasma hormone levels and with the regulation of the expression of different ion transporters/channels in gill cells (Perry 1997, Wong \& Chan 1999a,b, Evans 2002, Evans et al. 2005, Tse et al. 2006). Different models of ion transport in gill cells of both freshwater (FW) and seawater fish and the functional roles of the respective hormones have been proposed and summarized in recent reviews (Hwang et al. 2011, Takei et al. 2014). The results of these studies provide unequivocal evidence that strengthens our understanding of fish ion-osmoregulation. Among different ion-regulatory hormones, the glycoprotein STC1 plays an important role in plasma $\mathrm{Ca}^{2+}$ homeostasis in fish, but the underlying mechanisms of its post-receptor signaling pathways and their effects on gill cells remain mostly unknown.

STC1 is a glycosylated hypocalcemic hormone synthesized from a unique endocrine gland, the corpuscle of Stannis (CS), in bony fish (Wagner et al. 1986). A rise in serum $\mathrm{Ca}^{2+}$ levels stimulates STC1 release from the CS. STC1 reduces branchial and intestinal $\mathrm{Ca}^{2+}$ uptake but stimulates renal Pi reabsorption (Gerritsen \& Wagner 2005). The STC1 paralog STC2 has been cloned in fish (Luo et al. 2005, Shin \& Sohn 2009); it is, however, widely expressed in multiple tissues, and its function in fish is largely still not known. Yet the biological action of STC1 in inhibiting gill $\mathrm{Ca}^{2+}$ transport (GCAT) has been generally applied as a standard bioassay to test the hypocalcemic potency of CS extracts or recombinant STC1 proteins (Wagner et al. 1986, 1993, Olsen et al. 1996). Although this is the most recognized action of STC1, major gaps still exist in our knowledge of the mechanism behind the inhibition of GCAT by STC1. The identification of STC1 target cells is hindered by the lack of information on STC1 receptors. Although an STC1 receptor has not been cloned yet, indirect evidence indicates that STC1 receptors belong to the family of G-protein-coupled receptors (Lu et al. 1994).
Using isolated flounder proximal tubules, Lu et al. (1994) showed that STC1 treatment stimulated a PKA-dependent pathway via an elevation of cellular cAMP levels. This observation provided a hint for investigating the STC1mediated signaling cascade and possible downstream targets in $\mathrm{Ca}^{2+}$-transporting tissues.

Plasma $\mathrm{Ca}^{2+}$ concentration affects STC1 secretion from CS glands and thus the rate of GCAT. We proposed the hypothesis that in fish adapted to water with varying $\mathrm{Ca}^{2+}$ content, GCAT is also regulated by alteration of the expression of branchial STC1 receptors in response to STC1. To address this hypothesis, we aimed to elucidate the mechanism of STC1 binding and signaling in the fish gill. Our data indicated that branchial STC1 binding sites were significantly more numerous in the plasma membrane and were increased in fish acclimated in high- $\mathrm{Ca}^{2+}$ FW. The binding of STC1 stimulated cAMP signaling in both pavement cells (PVCs) and mitochondria-rich cells (MRC) to stimulate the expression of epithelial calcium channel (ecacl) and cyclooxygenase-2 (cox-2) to regulate $\mathrm{Ca}^{2+}$ homeostasis.

\section{Materials and methods}

\section{Animals, gill cells, and CS gland isolation}

Japanese eels (Anguilla japonica), weighing between 500 and $600 \mathrm{~g}$, were reared in fiberglass tanks supplied with charcoal-filtered, aerated tap water at $18-20^{\circ} \mathrm{C}$. They were placed under a $12 \mathrm{~h}$ light: $12 \mathrm{~h}$ darkness cycle for acclimation before experiments were performed. The fish were then divided into two groups: low- $\mathrm{Ca}^{2+} \mathrm{FW}$ (local tap water, $0.2 \mathrm{mM} \mathrm{Ca}^{2+}$ ) and high-Ca ${ }^{2+} \mathrm{FW}$ (local tap water with added $\mathrm{CaSO}_{4}, 2 \mathrm{mM} \mathrm{Ca}^{2+}$ ). After 14 days, the fish were sampled and killed by anesthesia in tap water containing 0.1\% MS-222 (Sigma). Gills were perfused with PBS (pH 7.7), and gill arches were excised, washed, and cut into small fragments for enzymatic digestion. After cell dissociation, resuspended gill cells were layered on a two-step Percoll gradient system $(1.03$ and $1.09 \mathrm{~g} / \mathrm{ml}$ in PBS) and centrifuged $(2000 \boldsymbol{g})$ at $15^{\circ} \mathrm{C}$ for $20 \mathrm{~min}$. The isolated gill cells at the interface of 1.03 and $1.09 \mathrm{~g} / \mathrm{ml}$ were collected and washed with PBS, followed by Hank's balanced salts solution (HBSS, Gibco). In some experiments, a three-step Percoll gradient (1.03/1.06/1.09 g/ml) was used for the isolation of specific cell types, specifically PVCs and MRCs, as described in our previous study (Wong \& Chan 1999b). The isolated gill cells were

Published by Bioscientifica Ltd 
incubated at $22^{\circ} \mathrm{C}$ for $1-2 \mathrm{~h}$ before experiments. CS glands of the fish were also collected and dissected for subsequent experiments.

\section{Expression constructs for eel STC1 fusion proteins}

STC1-V5 and STC1-alkaline phosphatase (AP) fusion proteins were generated by cloning the PCR-amplified, in-frame coding region of eel STC1 into pENTRTM/SD/ D-TOPO (Invitrogen) and pAPtag-5 vectors (GenHunter, Nashville, TN, USA), both according to the manufacturers' instructions. STC1 inserts were verified by DNA sequencing. STC1-V5 or STC1-AP expression vectors were transfected into the human embryonic kidney cell line (293FT) using Lipofectamine 2000 reagent (Invitrogen). The vectors without the insert (V5 alone or AP alone) were also transfected into 293FT cells as negative controls. Conditioned media were collected and concentrated 20-fold using Vivaspin 20 concentrators (GE Healthcare Life Sciences, Pittsburgh, PA, USA). The expression levels of STC1-fusion proteins were checked by western blotting.

The concentrations of STC1-fusion proteins were determined by an ELISA using the DuoSet ELISA Kit (R\&D Systems, Minneapolis, MN, USA), according to the manufacturer's instructions. Briefly, the high-binding, flat-bottomed polypropylene microplates were coated with goat anti-human STC1 antibody at room temperature overnight; they were then washed with PBS containing $0.05 \%$ Tween-20 (PBST) and blocked with the reagent diluent (PBS containing 1\% BSA, R\&D Systems) for $1 \mathrm{~h}$. Either samples or diluted STC1 standard (62.5$4000 \mathrm{pg} / \mathrm{ml}$ ) were added to the antibody-coated wells for $2 \mathrm{~h}$. The samples or standard were then washed with PBST and incubated with the biotinylated goat anti-human STC1 antibody for $2 \mathrm{~h}$. After the addition of tetramethylbenzidine substrate (R\&D Systems), the reaction was stopped with Stop Solution $\left(1 \mathrm{M} \mathrm{H}_{2} \mathrm{SO}_{4}\right)$. The absorbance at $450 \mathrm{~nm}$ was determined for each well using a microplate reader (Bio-Tek (Winooski, VT, USA), ELX800).

\section{Measurement of cAMP levels}

Isolated gill cells were incubated with i) CS extracts, $1 \mu \mathrm{g}$ of total protein (collected from fish adapted to low- or high$\left.\mathrm{Ca}^{2+} \mathrm{FW}\right)$, ii) $0.5 \mathrm{nM}$ STC1-V5, or iii) V5 alone in HBSS for $45 \mathrm{~min}$. To verify if any observed effects were from endogenous STC1 in the CS extracts, we repeated the experiment with a pre-incubation period using goat antiSTC1 antibody (R\&D Systems). Goat IgG (R\&D Systems), an isotype-matched antibody, was used as a control. Levels of cAMP were measured using a Lance cAMP 384 kit, according to the manufacturer's instructions (PerkinElmer Life Sciences, Waltham, MA, USA). The fluorescent signal was measured with a VICTOR X4 Multilabel Plate Reader (PerkinElmer Life Sciences), using excitation at $340 \mathrm{~nm}$ and emission at 615 and $665 \mathrm{~nm}$.

\section{In situ ligand binding assays}

To localize STC1 binding sites at the histological level, in situ ligand binding was performed using STC1-AP, as previously described (McCudden et al. 2002, Wu et al. 2006). Paraformaldehyde-fixed gill tissues were de-waxed, rehydrated in graded ethanol, and rinsed in PBST containing $0.1 \%$ Tween 20. The experimental procedure involved pretreating the tissue sections with 3\% normal goat serum in PBST to reduce nonspecific binding, then incubating them overnight at $4{ }^{\circ} \mathrm{C}$ with: i) V5 alone, ii) $0.5 \mathrm{nM}$ STC1-V5, or iii) $0.5 \mathrm{nM}$ STC1-V5 plus 50 nM STC1-AP (for competitive binding). The slides were incubated at room temperature with mouse anti$\mathrm{Na}^{+} / \mathrm{K}^{+}$-ATPase-subunits (1:200; Na $\alpha 5$, Developmental Studies Hybridoma Bank, University of Iowa) for $1 \mathrm{~h}$, and then incubated with a cocktail of Alexa Fluor 568 goat antimouse IgG (1:200; Life Technologies) and anti-V5-FITC (1:500; Life Technologies). The slides were washed three times for $15 \mathrm{~min}$ in PBST after each antiserum application. Nuclei were stained with DAPI mounting medium (Vector Laboratories, Burlingame, CA, USA). The localization of $\mathrm{ECaCl}$ was determined in gill sections exposed to rabbit anti-ECaCl (1:40; Abcam, New Territories, Hong Kong, China), and then incubated for $1 \mathrm{~h}$ with Alexa Fluor 488 goat anti-rabbit IgG (1:200). The slides were examined using an EVOS FLoid Cell Imaging Station (Life Technologies).

\section{STC1 receptor-binding assay}

An STC1 receptor-binding assay was conducted using nuclear, mitochondrial, and plasma membrane fractions of gill cells. Cell fractionation was performed and verified following methods described previously (McCudden et al. 2002). Briefly, gill cells were Dounce-homogenized in $1 \mathrm{ml}$ of $0.1 \mathrm{M}$ Tris- $\mathrm{HCl}$ ( $\mathrm{pH} 7.6$ ) containing $0.25 \mathrm{M}$ sucrose and $5 \mathrm{mM}$ EDTA. The homogenate was then centrifuged twice at $1000 \boldsymbol{g}$ for $15 \mathrm{~min}$, once at $15000 \boldsymbol{g}$ for $30 \mathrm{~min}$, and finally at $100000 \boldsymbol{g}$ for $90 \mathrm{~min}$, which thereby isolated crude nuclear, mitochondrial, and plasma membrane fractions respectively. The isolated subcellular fractions were then resuspended in $50 \mathrm{mM}$ HEPES ( $\mathrm{pH}$ 7.6) and protein concentrations were quantified. Samples were stored at $-80^{\circ} \mathrm{C}$.

Published by Bioscientifica Ltd. 
For the binding assay, $2.5 \mu \mathrm{g}$ aliquots of each subcellular fraction were incubated in i) AP alone, ii) 0.5 nM STC1-AP, or iii) 0.5 nM STC1-AP plus 50 nM STC1V5 (for competitive binding) in HBSS containing 0.1\% BSA (HBHA; pH 7.5) using an orbital shaker (20 r.p.m., $3 \mathrm{D} /$ fixed $20^{\circ} \mathrm{C}$ ) for $2 \mathrm{~h}$. To separate bound and free STC$\mathrm{AP}$ ligands, samples were centrifuged for $3 \mathrm{~min}$ at $10000 \boldsymbol{g}$ to pellet the protein and then washed twice in $1 \mathrm{ml}$ of ice-cold HBHA. The pellets were then solubilized in $15 \mu \mathrm{l}$ of $1 \%$ Triton X-100 in $10 \mathrm{mM}$ Tris- $\mathrm{HCl}$, (pH 8.0) to detect AP activity. Specific binding was determined by subtracting $\mathrm{AP}$ activity in the negative controls (AP alone) from $\mathrm{AP}$ activity in samples incubated with STC1-AP. To examine the specific activity of the STC1-AP ligand, data were converted into units of STC1 for the calculation of $K_{\mathrm{d}}$ and $B_{\text {max }}$ using GraphPad Prism (LaJolla, CA, USA).

AP activity was measured using the Phospha-Light SEAP Reporter Gene Assay System for the detection of placental AP activity, according to the manufacturer's instructions (Novex, Life Technologies). Briefly, samples that had been mixed with a dilution buffer (1:1) were heated at $65{ }^{\circ} \mathrm{C}$ for $30 \mathrm{~min}$, and then cooled to room temperature. An aliquot $(25 \mu \mathrm{l})$ of the sample mix was then incubated with $25 \mu \mathrm{l}$ of assay buffer, and then $25 \mu \mathrm{l}$ or reaction buffer at room temperature were added. Luminescence was measured using the VICTOR X4 Multilabel Plate Reader (PerkinElmer Life Sciences).

\section{Ratiometric digital imaging of $\left[\mathrm{Ca}^{2+}\right]_{i}$}

Gill cells were seeded on collagen-coated $(50 \mu \mathrm{g} / \mathrm{ml}$, Cultrex, Gaithersburg, MD, USA), round (25 mm) glass coverslips with a density of $2 \times 10^{5}$ cells/coverslip. Slides were maintained in a phenol-red-free HBSS medium that was supplemented with $10 \%$ fetal bovine serum in a $22^{\circ} \mathrm{C}$ humidified chamber. The cells were then incubated with $1 \mu \mathrm{M}$ Fura-2/AM in HBSS medium for $2 \mathrm{~h}$ at $22^{\circ} \mathrm{C}$. After dye loading, the cells were washed twice, also with HBSS medium, and the coverslips were then secured in a small chamber containing $500 \mu \mathrm{l}$ of the medium. Gill cells were treated with i) thapsigargin (TG) $(2 \mu \mathrm{M}$, Calbiochem, San Diego, CA, USA), ii) a co-treatment of TG with $0.5 \mathrm{nM}$ STC1-V5 or V5, or iii) a pretreatment with inhibitors (i.e. PKA inhibitor (100 nM 14-22 Amide, Calbiochem) or COX2 inhibitor ( $2 \mu \mathrm{M}$ NS-398, Cayman, Ann Arbor, MI, USA)). The cells were imaged using an inverted microscope (Nikon) equipped with a CCD camera (CoolSnap $\mathrm{HQ}$, Tucson, AZ, USA). Cell images were captured with excitation wavelengths of 340 and $380 \mathrm{~nm}$ and an emission wavelength of $510 \mathrm{~nm}$. Images were analyzed using the
MetaFluor Software (Sunnyvale, CA, USA). Images containing 30-40 cells were selected, and an excitation ratio for wavelengths of 340:380 $\mathrm{nm}$ was recorded.

\section{LDH activity analysis}

Isolated gill cells were incubated in $200 \mu \mathrm{l} \mathrm{HBSS}$ medium for $4 \mathrm{~h}$ with the following: i) $2 \mu \mathrm{M}$ TG (Calbiochem), ii) a co-treatment of TG with $0.5 \mathrm{nM}$ STC1-V5 or V5 alone, or iii) a co-treatment of TG with $0.5 \mathrm{nM}$ STC1-V5 or V5 alone, plus either a PKA inhibitor (100 nM 14-22 Amide, Calbiochem) or a COX-2 inhibitor ( $2 \mu \mathrm{M}$ NS-398, Cayman). After incubation, supernatants were collected for measuring LDH activity with an LDH Cytotoxicity Assay Kit (Cayman), according to the manufacturer's instructions. Absorbance signals were detected at $490 \mathrm{~nm}$ using a microplate reader (Bio-Tek, ELX800).

\section{Real-time PCR analysis}

Isolated gill cells in HBSS medium were treated with i) V5 alone, ii) $0.5 \mathrm{nM} \mathrm{STC1-V5,} \mathrm{or} \mathrm{iii)} 2 \mu \mathrm{M}$ TG for $4 \mathrm{~h}$ at $22^{\circ} \mathrm{C}$. In some treatments, the cells were pre-incubated for $5 \mathrm{~min}$ with the PKA inhibitor (100 nM 14-22 Amide, Calbiochem). Purified RNA with a ratio of 1.8:2.0 for A260:A280 was used. Briefly, $0.5 \mu \mathrm{g}$ of total cellular RNA was reverse transcribed using a high-capacity RNA-to-cDNA Kit (Applied Biosystems). PCRs were conducted with the StepOne realtime PCR system using the power SYBR Green PCR master mix (Applied Biosystems). Verified gene-specific primers for Japanese eels were used ( $g a p d h$-F: GCGCCAGCCAGAACATCATC, gapdh-R: CGTTAAGCTCGGGGATGACC; STC1-F: CTCAGAGGTTCAGGAGGAGT, STC1-R: GGTGCTGTAGTACCTGTTGG; $c o x-2-F$ : TAGCCCACCAACCTACAATG, cox-2-R: TGAGCAAAAAAGGCAAACAC; and ecacl-F: GCAGCCCAATAAAACCATCGC, ecacl-R: CCACCACATTGCCCTCCTG). We referenced parallel amplifications of the cloned PCR fragments with known concentrations to calculate the copy number of transcripts for each sample. We tested for the occurrence of primer-dimers and secondary products using melting curve analysis. Our results indicated that the amplification was specific for each individual set of primers. Control amplification was done either without reverse transcriptase or without RNA. The relative expression ratio of a target gene ((STC1, cox-2, or ecacl)/gapdh) was calculated according to a previously described method (Pfaffl 2001): Expression ratio $=E_{\text {target }}^{\text {CPtarget (control-treatment) }} / E_{\text {gapdh }}^{\text {CPgapdh (control-treatment) }}$, where $E=10^{(-1 / \text { slope })}$ and CP is the crossing point at which fluorescence rises above background levels.

Published by Bioscientifica Ltd. 


\section{Western blot analysis}

Protein lysates were subjected to electrophoresis in $8 \%$ polyacrylamide gels. Lysates contained $20-40 \mu \mathrm{g}$ of total protein in a radioimmunoprecipitation assay buffer mixed with $5 \times$ SDS loading buffer $(250 \mathrm{mM}$ Tris- $\mathrm{HCl}$ at pH 6.8, 10\% SDS, 50\% glycerol, 5\% $\beta$-mercaptoethanol, $62.5 \mathrm{mM}$ EDTA, and $0.1 \%$ bromophenol blue). Postelectrophoresis, the gels were blotted onto PVDF membranes (PerkinElmer Life Sciences). Western blotting was conducted using rabbit antibodies against STC1 (Origene, Rockville, MD, USA) and AP (GenHunter) as well as mouse antibodies against V5 (Invitrogen) and His (GE Healthcare Life Science), and then the gels were incubated with HRP-conjugated goat anti-rabbit or antimouse antibody (1:4000; Bio-Rad). Specific bands were visualized using a chemiluminescent reagent (WesternLightening Plus, PerkinElmer Life Sciences). For some experiments, the blots were then washed in PBST and re-probed with mouse monoclonal anti-fish actin antibody (1:100; JLA20, Developmental Studies Hybridoma Bank).

\section{Statistical analysis}

Drug treatments were performed in triplicate for each experiment, and every experiment was repeated at least three times. All data are represented as means \pm s.E.M. Statistical significance was assessed with Student's $t$-test or one-way ANOVA, followed by Duncan's multiple range tests. Groups were considered significantly different if $P<0.05$.
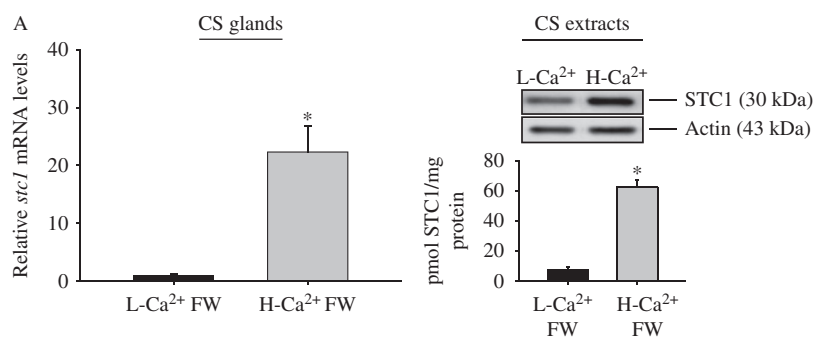

\section{Figure 1}

Effects of CS extracts on the production of CAMP in gill cells. (A) Real-time PCR (left), western blotting analysis (upper right), and ELISA (lower right) of STC1 expression in CS extracts collected from eels adapted to low- $\mathrm{Ca}^{2+}$ $\mathrm{FW}\left(\mathrm{L}-\mathrm{Ca}^{2+} \mathrm{FW}\right)$ or high-Ca ${ }^{2+} \mathrm{FW}\left(\mathrm{H}-\mathrm{Ca}^{2+} \mathrm{FW}\right)$ conditions. (B) Effects of $\mathrm{CS}$ extract treatments on CAMP production in gill cells. (C) Effects of STC1

\section{Results}

\section{Effects of CS extracts on the production of CAMP in gill cell cultures}

The CS extracts from eels adapted to low- or high- $\mathrm{Ca}^{2+} \mathrm{FW}$ conditions were used to test their effects on cAMP production in gill cell cultures. Both real-time PCR and western blot analysis revealed greater STC1 expression in the CS extracts from fish adapted to high- $\mathrm{Ca}^{2+} \mathrm{FW}$ (Fig. 1A). The results of ELISA analysis indicated that the STC1 content in CS extracts from fish adapted to low- and high- $-\mathrm{Ca}^{2+}$ FW were $8.2 \pm 1.27$ and $62.3 \pm 4.53 \mathrm{pmol} / \mathrm{mg}$ protein respectively (Fig. 1A).

CS extracts from both groups of eels significantly induced increases in the cAMP levels in the gill cells (Fig. 1B). However, the effect of the CS extract from fish adapted to high- $\mathrm{Ca}^{2+} \mathrm{FW}$ was significantly greater. To test if our results were indeed caused by the presence of STC1, rather than other compounds in the extracts, we conducted an antibody-neutralizing experiment against STC1. The use of STC1 antibody abolished the effects of the extracts (Fig. 1C).

\section{The binding of the STC1 recombinant protein on paraffin-embedded gill tissues of fish adapted to low- and high-Ca ${ }^{2+}$ FW}

To verify if the STC1 recombinant protein (STC1-V5) was biologically active, the cAMP production assay was conducted using gill cell cultures. The presence of the recombinant protein in the conditioned medium of STC1V5-transfected 293FT cells was verified using an antibody
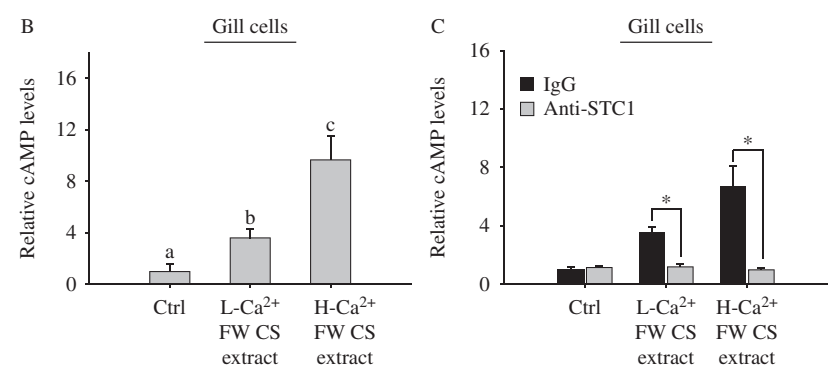

neutralizing antibody on CS extract-induced CAMP levels in gill cells. ${ }^{*} P<0.05$, as compared with the respective control, Student's $t$-test. Bars with the same letter are not significantly different according to the results of one-way ANOVA followed by Duncan's multiple range tests $(P<0.05)$.

Published by Bioscientifica Ltd. 
against STC1 or V5 (Fig. 2A). The treatment of gill cell cultures with the recombinant protein STC1-V5 stimulated an elevation of cytosolic cAMP levels. The stimulatory effect was abolished when the cultures were co-treated with the STC1 neutralizing antibody (Fig. 2B).

To determine the spatial expression profile of STC1 receptors, an STC1-V5 binding assay was conducted. As shown in Fig. 2C, binding was detected on both gill PVCs and MRCs at the lamellar and inter-lamellar regions (Fig. 2C, ii and v). A significant increase in STC1-V5 binding was detected in the gill sections prepared from fish adapted to high- $\mathrm{Ca}^{2+}$ FW (Fig. 2C, v). The spatial localization of the STC1-V5 binding sites indicated that the expression of STC1 receptors was not restricted to a specific epithelial cell type. To validate this observation, we conducted cAMP assays using gill PVCs and MRCs isolated by three-step Percoll-gradient centrifugation. Both cell types responded to STC1-V5 with significant inductions of cAMP levels (Fig. 2D).

\section{The binding of the STC1 recombinant protein (STC1-AP) to subcellular fractions of gill preparations}

The recombinant protein STC1-AP was prepared and verified with western blotting using antibodies against AP, His, or STC1 (Fig. 3A). The saturation binding assays were carried out on isolated gill nuclear, mitochondrial, and plasma membrane preparations, and they detected high-affinity and high-capacity binding sites in all three preparations. Figure 3B shows the saturation binding data of STC1-AP and AP on the isolated gill plasma membrane preparations from the low- $\mathrm{Ca}^{2+}$ and the high- $\mathrm{Ca}^{2+}$ conditions. The binding data for mitochondrial and nuclear preparations are shown in Supplementary Fig. 1, see section on supplementary data given at the end of this article.

The specific STC1-AP binding values $\left(K_{\mathrm{d}}\right.$ and $\left.B_{\max }\right)$ were then calculated for each of the individual subcellular preparations (Fig. 3C and D). Under the low- $\mathrm{Ca}^{2+}$ conditions, $K_{\mathrm{d}}(\mathrm{nM})$ and $B_{\max }$ (pmol/mg protein) for the
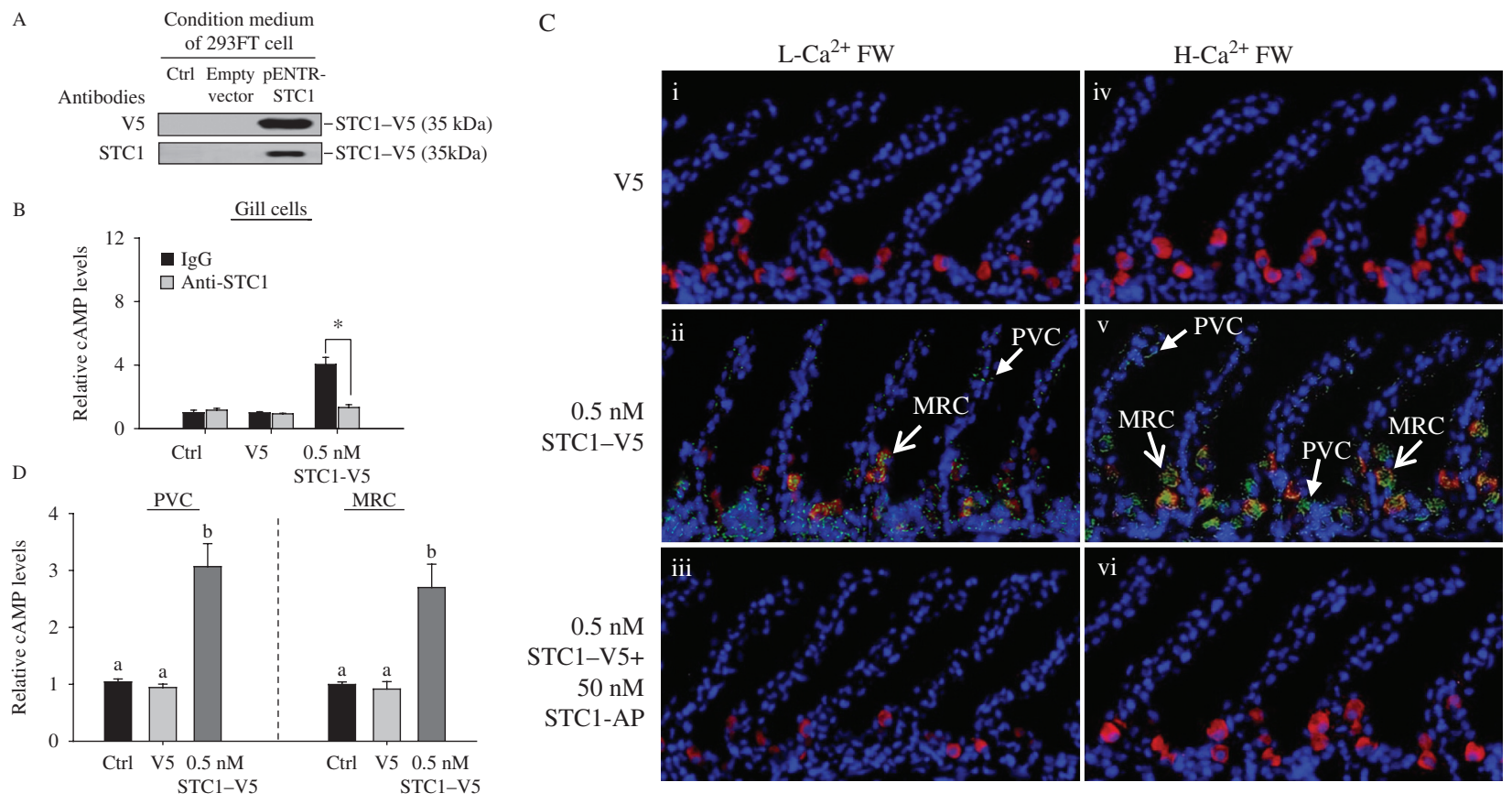

Figure 2

The binding of the STC1 recombinant protein (STC1-V5) to gill tissues of fish adapted to low-Ca ${ }^{2+} \mathrm{FW}\left(\mathrm{L}-\mathrm{Ca}^{2+} \mathrm{FW}\right)$ or high-Ca ${ }^{2+} \mathrm{FW}\left(\mathrm{H}-\mathrm{Ca}^{2+} \mathrm{FW}\right)$. (A) Western blotting analysis of the expression levels of STC1 recombinant protein STC1-V5 in conditioned media of human embryonic kidney cell line (293FT). Antibodies against V5 and STC1 were used to detect the presence of STC1-V5. (B) Effects of STC1-V5 on CAMP production by gill cells. The use of an STC1 neutralizing antibody abolished the stimulatory effect. ${ }^{*} P<0.05$, as compared with the respective control, Student's $t$-test.

(C) Specific binding of STC1-V5 (green) to gill tissues of fish adapted to $\mathrm{L}-\mathrm{Ca}^{2+} \mathrm{FW}$ or $\mathrm{H}-\mathrm{Ca}^{2+} \mathrm{FW}$. The sections were counterstained with $\mathrm{Na} \alpha 5$ (red, a marker of mitochondria-rich cells (MRCs)) and DAPI fluorescence. Gill sections were incubated with V5 alone (i, iv), 0.5 nM STC1-V5 (ii, v), or 0.5 nM STC1-V5 plus $50 \mathrm{nM}$ STC1-AP (iii, vi). (D) The effects of STC1-V5 on CAMP levels in isolated gill pavement cells (PVCs) and MRCs. Bars with the same letter are not significantly different according to the results of one-way ANOVA followed by Duncan's multiple range tests $(P<0.05)$.

Published by Bioscientifica Ltd. 
A
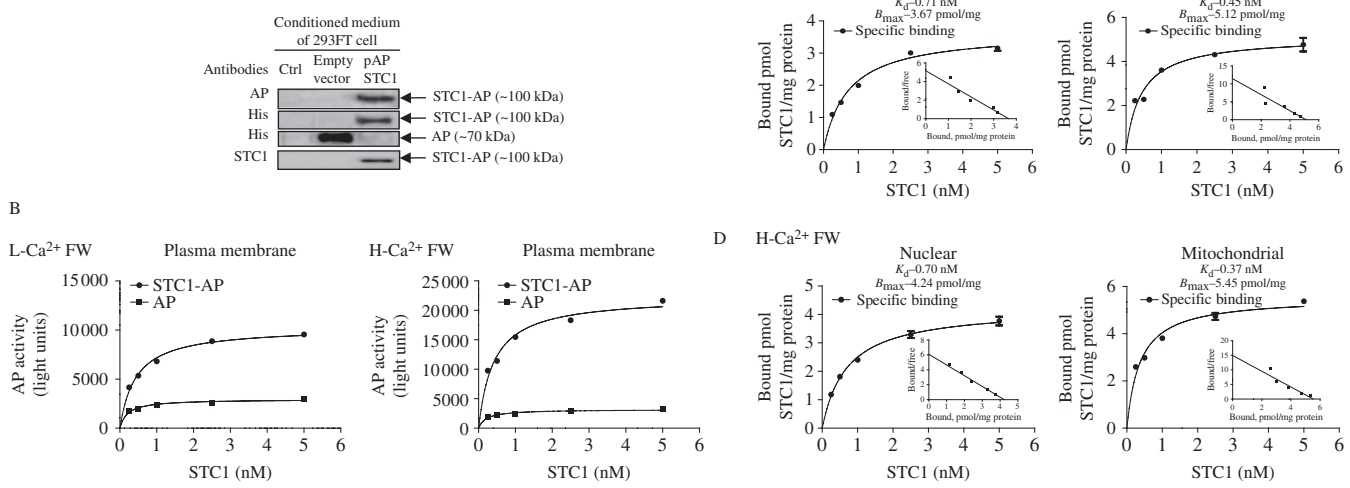

Figure 3

Receptor-binding assays on fish gills. (A) Western blotting analysis of expression levels of the recombinant protein STC1-AP. Antibodies against AP, His, and STC1 were used to detect the presence of STC1-AP in conditioned media of human embryonic kidney cell line (293FT). (B) Saturation-binding assays revealed the presence of saturable, highaffinity binding sites on the subcellular fractions of gill preparations. The raw binding data were obtained using STC1-AP and AP. (C and D) Specific

nuclear, mitochondrial, and plasma preparations were $0.71 \pm 0.08$ and $3.67 \pm 0.13,0.45 \pm 0.08 \mathrm{nM}$ and $5.12 \pm$ 0.25 , and $0.37 \pm 0.02 \mathrm{nM}$ and $5.54 \pm 0.08$ respectively (Fig. $3 \mathrm{C}$ ). Under the high-Ca ${ }^{2+}$ conditions, $K_{\mathrm{d}}$ and $B_{\max }$ for the nuclear, mitochondrial, and plasma preparations were $0.70 \pm 0.09$ and $4.24 \pm 0.18,0.37 \pm 0.05$ and $5.45 \pm$ 0.20 , and $0.36 \pm 0.05$ and $12.99 \pm 0.44$ respectively (Fig. 3D). There were no significant changes in the $K_{\mathrm{d}}$ of all the subcellular preparations obtained under high- or low-Ca ${ }^{2+}$ conditions. However, a significant increase in $B_{\max }$ was identified in the plasma membrane preparations from eels exposed to high- $\mathrm{Ca}^{2+}$ conditions. Levels of nonspecific binding were similar among the samples. Using STC1-V5 it was possible to display the binding of STC1-AP.

\section{Effects of STC1-V5 on intracellular $\mathrm{Ca}^{2+}$ levels, expression of ecacl and cox-2}

In this part of the present study, we used TG to induce an increase in cytosolic $\mathrm{Ca}^{2+}$, which allowed us to test for the inhibitory effect of STC1 using the recombinant protein STC1-V5 as the ligand. TG treatment induced an increase in intracellular $\mathrm{Ca}^{2+}\left[\mathrm{Ca}^{2+}\right]_{\mathrm{i}}$ (Fig. 4A, i). The addition of V5 (Fig. 4A, ii and iii) or STC1-V5 alone (Fig. 4A, iv) had no noticeable effects on $\left[\mathrm{Ca}^{2+}\right]_{\mathrm{i}}$. The co-treatment of TG with STC1-V5, however, abolished the effect of increased $\left[\mathrm{Ca}^{2+}\right]_{\mathrm{i}}$ (Fig. 4A, v). The co-treatment with the PKA inhibitor (PKAi, 14-22 Amide) or the COX-2 inhibitor (NS-398) significantly reduced the effect of STC1-V5,
STC1-AP binding in the subcellular samples from eels adapted to $\mathrm{L}-\mathrm{Ca}^{2+} \mathrm{FW}$ (C) or $\mathrm{H}_{-} \mathrm{Ca}^{2+} \mathrm{FW}$ (D) are shown after data transformation. Scatchard plots derived from the saturation binding data are shown as inserts. Each data point represents the mean \pm s.E.M. of three replicates. Each binding assay was repeated three times. The data transformation produced an estimated $K_{\mathrm{d}}$ and $B_{\max }$.

whereas the inhibitor alone had no noticeable effects (Fig. 4A, vi, vii, viii and ix).

To address the functional outcome of STC1's effects on the TG-induced increase in cytosolic $\mathrm{Ca}^{2+}$, a cytotoxicity assay was conducted. STC1 significantly reduced TG-induced cytotoxicity (Fig. 4B). Additionally, cotreatment with the inhibitors significantly reduced the protective effect of STC1.

The gill tissues of fish adapted to low- $\mathrm{Ca}^{2+} \mathrm{FW}$ or high-Ca ${ }^{2+}$ FW expressed ECaCl (Supplementary Fig. 2, see section on supplementary data given at the end of this article). To elucidate the effects of STC1-V5 on the downstream targets associated with $\mathrm{Ca}^{2+}$ regulation, the expression levels of ecacl and cox-2 were measured. STC1V5 treatment significantly increased cox-2 but reduced ecacl mRNA expression levels (Fig. 5A and B). The addition of PKAi abolished the action of STC1-V5.

\section{Discussion}

The results of the present study indicated a possible mechanism for STC1 inhibition of GCAT, using various preparations of STC1 receptor ligands (CS extracts, recombinant STC1 proteins) and bioassays (cAMP, in situ ligand binding, receptor binding). Our results support the hypothesis that functional STC1 receptors are present in gill cells. In response to STC1 binding, the expression level of the downstream target, ecacl, was modulated to reduce GCAT in order to regulate systemic $\mathrm{Ca}^{2+}$ levels.

Published by Bioscientifica Ltd 

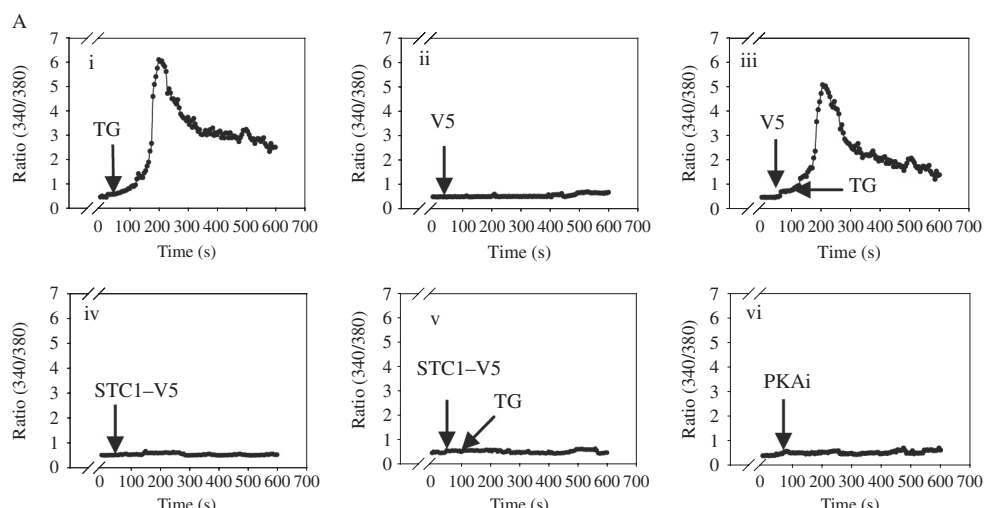

B
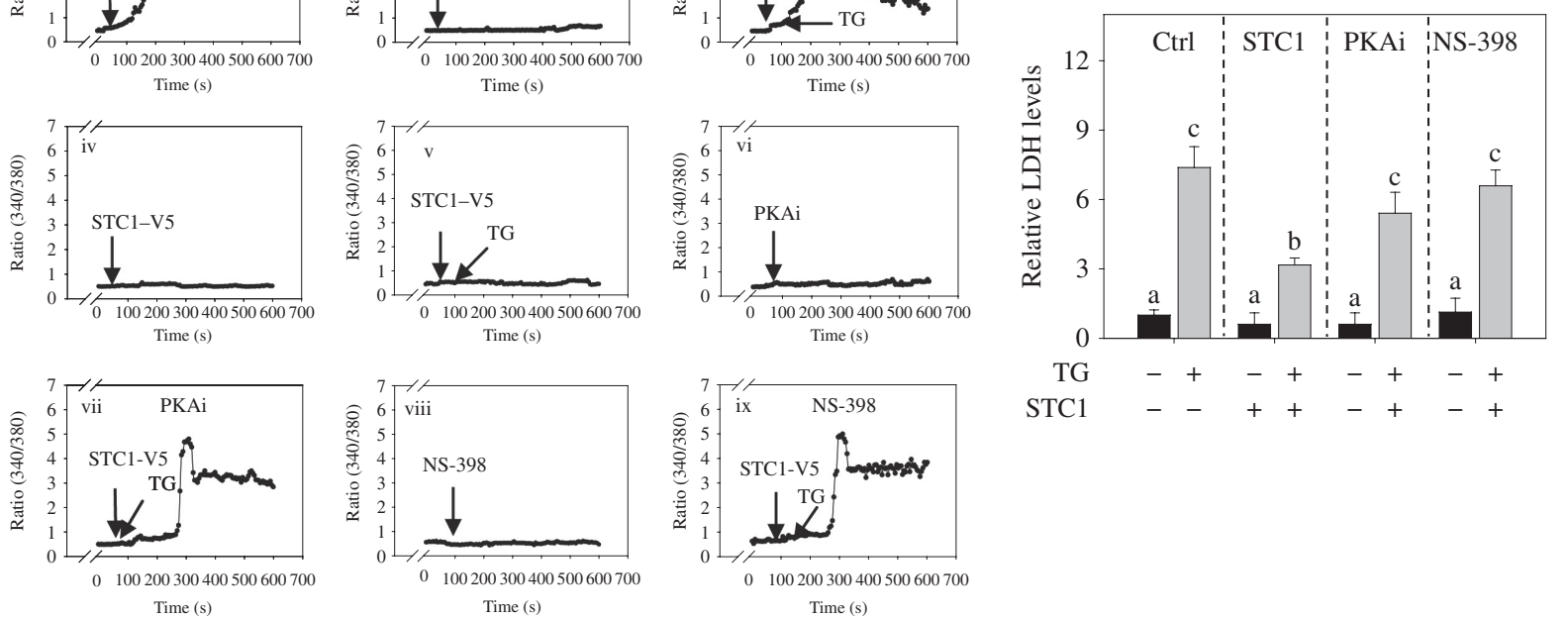

\section{Figure 4}

Effects of thapsigargin (TG) and/or STC1-V5 on intracellular $\mathrm{Ca}^{2+}$ levels and viability of gill cells. (A) TG treatment increased $\left[\mathrm{Ca}^{2+}\right]_{i}$ as measured using a $\mathrm{Ca}^{2+}$ detection dye, Fura 2-AM (i). There were no noticeable effects on $\left[\mathrm{Ca}^{2+}\right]_{\mathrm{i}}$ when the cells were treated with either V5 or STC1-V5 (ii, iii and iv). The STC1-V5 co-treatment abolished TG-induced $\left[\mathrm{Ca}^{2+}\right]_{i}(\mathrm{v})$. The use of inhibitors PKAi or NS-398 reduced the effects of STC1-V5 on TG-induced

Results of previous research have indicated that STC1 treatment elevates cellular cAMP levels in flounder proximal tubules and thereby stimulates a PKA-dependent pathway (Lu et al. 1994). However, as far as we are aware, no prior study exists that tests the signaling pathway of STC1 using fish gills, one of the hormone's major tissue targets. In the present study, we therefore adopted the gill cell culture model to validate the effect of STC1 on cAMP levels. Our results indicated clearly that there was a significant upregulation of cAMP in gill cells upon treatment with CS extracts. Specifically, we demonstrated that a significantly greater stimulation of cAMP production occurred when CS extracts of fish adapted to high- $\mathrm{Ca}^{2+}$ rather than low- $\mathrm{Ca}^{2+}$ FW conditions were used. This result is primarily an effect of the greater amount of STC1 synthesized and stored in the glands of fish adapted to high-Ca ${ }^{2+} \mathrm{FW}$. We also ruled out possible effects from other proteins in the CS extracts via the application of a neutralizing antibody, which confirmed the specific action of STC1. Moreover, the use of the STC1 recombinant protein STC1-V5 resulted in a similar effect on the stimulation of cAMP production in gill cell cultures. Taken together, this part of study indicated that STC1-signaling was mediated by cAMP, which supported the results of previous studies.
$\left[\mathrm{Ca}^{2+}\right]_{\mathrm{i}}(\mathrm{vi}$, vii, viii and ix). (B) Effects of TG, STC1-V5, and/or inhibitors on the viability of gill cells as determined by LDH cytotoxicity assay. STC1-V5 reduced TG-induced cytotoxicity, whereas co-treatment with the inhibitor reduced the effects of STC1-V5. Bars with the same letter are not significantly different according to the results of one-way ANOVA followed by Duncan's multiple range tests $(P<0.05)$.

Next, we showed that environmental/plasma $\mathrm{Ca}^{2+}$ levels affect changes to STC1 binding sites in fish gills. To our knowledge, the present study is the first to expressly demonstrate a connection between these two factors in this particular tissue. Specifically, the results of our in situ ligand binding assay clearly revealed a significant increase in STC1 binding sites in the gills of fish adapted to high$\mathrm{Ca}^{2+}$ as opposed to low-Ca ${ }^{2+}$ FW. In addition, the results of the receptor-binding assay that used subcellular fractions demonstrated specific binding of STC1 to plasma membrane, mitochondrial, and nuclear preparations. The estimated $K_{\mathrm{d}}$ of all the subcellular preparations of gills ranged from 0.36 to $0.71 \mathrm{nM}$, which is similar to the $K_{\mathrm{d}}$ from a STC1 receptor-binding study that used mammalian kidney and liver tissues (0.25-0.8 nM) (McCudden et al. 2002), but they were tenfold lower than those of a study that used adipocyte membranes $(7.9 \mathrm{nM}$ ) (Paciga et al. 2005). Our results indicated that both plasma membrane and mitochondrial preparations showed greater binding affinities to STC1 than nuclear preparation did. More specifically, the significant increase in $B_{\max }$ in the gill plasma membranes from fish adapted to high- $\mathrm{Ca}^{2+}$ FW might indicate an increased expression of STC1 receptors in these cells. This observation supports the hypothesis

Published by Bioscientifica Ltd. 

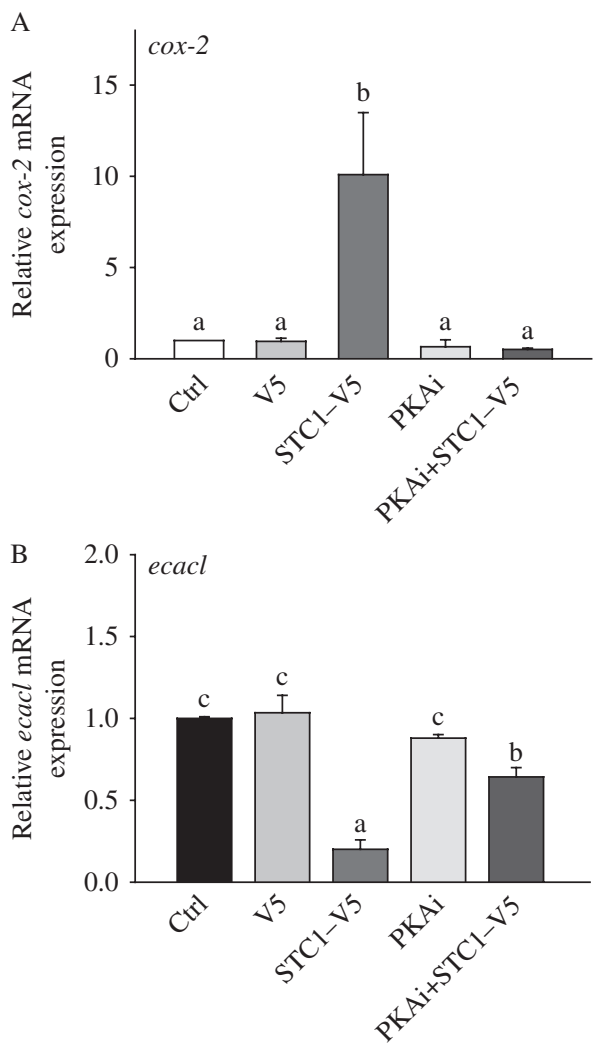

\section{Figure 5}

Effects of STC1-V5 treatment on the expression levels of cyclooxygenase-2 (cox-2) and epithelial $\mathrm{Ca}^{2+}$ channel (ecacl) in gill cells. (A) The expression levels of cox-2 mRNA in gill cells were determined using real-time PCR. A significant upregulation of cox-2 expression upon STC1-V5 treatment was detected. Co-treatment with the inhibitor PKAi reduced the upregulation. (B) Effects of STC1-V5 treatment on the mRNA expression levels of ecacl in gill cells. A significant reduction of ecacl was noted upon STC1-V5 treatment, whereas PKAi co-treatment reduced the effects. Bars with the same letter are not significantly different according to the results of one-way ANOVA followed by Duncan's multiple tests $(P<0.05)$.

that the expression levels of branchial STC1 receptors were altered in response to increased water or plasma $\mathrm{Ca}^{2+}$ content. In terms of the specific cells that express STC1 receptors, gill chloride cells (CCs/MRCs) have long been suggested to be the targets of STC1. However, to our knowledge, very few studies exist that have definitively demonstrated this, and what little data are available are indirect (Flik \& Verbost 1993, Chan \& Wong 1997). In the present study, the increase in STC1 binding was observed across both the lamellar and inter-lamellar regions of the gill sections. Furthermore, we found that both PVCs and MRCs responded to STC1 stimulation with elevated cytosolic cAMP levels. This result indicated that both gill PVC and MRC expressed STC1 receptors.

Finally, our results give further insight into the underlying mechanism behind the STC1 inhibition of
GCAT and add to a small body of work that addresses this gap in our understanding. Results of previous research have indicated that CS extracts stimulate plasma membrane $\mathrm{Ca}^{2+}$-ATPase in rainbow trout gills (Ma \& Copp 1978) and, furthermore, that downregulation of STC1 in zebrafish embryos caused upregulation of ecacl expression (Tseng et al. 2009). Intriguingly, the mammalian STC paralog STC2 has been shown to negatively regulate extracellular $\mathrm{Ca}^{2+}$ influx via a store-operated $\mathrm{Ca}^{2+}$ channel (Zeiger et al. 2011). To illustrate the role of STC1 in intracellular $\mathrm{Ca}^{2+}$ homeostasis, we conducted $\mathrm{Ca}^{2+}$ imaging experiments using the chemical inhibitor TG to block the action of sarcoplasmic and endoplasmic reticulum $\mathrm{Ca}^{2+}$-ATPase (SERCA). The inhibition of SERCA is known to cause a rapid leakage of $\mathrm{Ca}^{2+}$ into the cell cytosol (Thastrup et al. 1990). In this study, STC1 functioned to reduce the TG-induced elevation of cytosolic $\mathrm{Ca}^{2+}$ levels, which was found to be mediated by cAMP. Intriguingly, using an inhibitor, NS-398, of COX-2, a prostaglandin-endoperoxide synthase known to stimulate the activity of SERCA, it was possible to block the action of STC1. The study revealed that COX-2 may be a possible downstream target of STC1, and this observation was supported by a follow-up experiment that indicated that STC1 induced upregulation of COX-2 expression in the gill cells. Moreover, STC1 treatment also inhibited ecacl expression. Because $\mathrm{ECaCl}$ is an important $\mathrm{Ca}^{2+}$ gatekeeper, ecacl inhibition may be one mechanism by which STC1 regulates systemic $\mathrm{Ca}^{2+}$ levels. Our findings in this regard mirror previous results for the zebrafish embryo (Tseng et al. 2009).

Overall, the present study builds on existing knowledge that STC1 acts on gills to inhibit GCAT by offering a mechanism for this action. The study provides direct evidence of STC1 binding, signaling, and mechanistic action in fish gills. Both gill PVCs and MRCs expressed STC1 receptors, which mediate cAMP signaling to regulate the expression of $\mathrm{ECaCl}$ and $\mathrm{COX}-2$. In turn, the gatekeeper proteins reduce GCAT to regulate systemic $\mathrm{Ca}^{2+}$ levels. The results of our previous study revealed the role of gill $\mathrm{Ca}^{2+}$-sensing receptor (CaSR) in stimulating the expression of STC1 in gill cells (Gu et al. 2014). More recently, Lin et al. (2014) reported the function of CaSR in regulating the expression of the hypercalcemic hormone parathyroid hormone 1 (PTH1) and STC1 using a zebrafish model. Both PTH1 and STC1 have been demonstrated to modulate the expression of $\mathrm{ECaCl}$ in affecting systemic $\mathrm{Ca}^{2+}$ homeostasis, presumably via a cAMP pathway. Further investigations of the possible counterbalancing mechanism of STC1/PTH1 toward GCAT are warranted.

Published by Bioscientifica Ltd. 


\section{Supplementary data}

This is linked to the online version of the paper at http://dx.doi.org/10.1530/ JME-14-0320.

\section{Declaration of interest}

The authors declare that there is no conflict of interest that could be perceived as prejudicing the impartiality of the research reported.

\section{Funding}

This work was supported by a General Research Grant (grant number GRF 261610), Hong Kong Baptist University (to C K C Wong).

\section{References}

Chan DK \& Wong CK 1997 Functional partition of cells in the gill epithelium of the Japanese eel, Anguilla japonica, and the role of hormones. Fish Physiology and Biochemistry 17 405-413. (doi:10.1023/ A:1007701826203)

Evans DH 2002 Cell signaling and ion transport across the fish gill epithelium. Journal of Experimental Zoology 293 336-347. (doi:10.1002/ jez.10128)

Evans DH, Piermarini PM \& Choe KP 2005 The multifunctional fish gill: dominant site of gas exchange, osmoregulation, acid-base regulation, and excretion of nitrogenous waste. Physiological Reviews 85 97-177. (doi:10.1152/physrev.00050.2003)

Flik G \& Verbost PM 1993 Calcium transport in fish gills and intestine. Journal of Experimental Biology 184 17-29.

Gerritsen ME \& Wagner GF 2005 Stanniocalcin: no longer just a fish tale. Vitamins and Hormones 70 105-135. (doi:10.1016/S0083-6729(05) 70004-2)

Gu J, Law AY, Yeung BH \& Wong CK 2014 Activation of gill $\mathrm{Ca}^{2+}$-sensing receptor as a protective pathway to reduce $\mathrm{Ca}^{2+}$-induced cytotoxicity. Journal of Molecular Endocrinology 53 155-164. (doi:10.1530/JME-14-0060)

Hwang PP, Lee TH \& Lin LY 2011 Ion regulation in fish gills: recent progress in the cellular and molecular mechanisms. American Journal of Physiology. Regulatory, Integrative and Comparative Physiology $\mathbf{3 0 1}$ R28-R47. (doi:10.1152/ajpregu.00047.2011)

Lin $\mathrm{CH}$, Su CH \& Hwang PP 2014 Calcium-sensing receptor mediates $\mathrm{Ca}^{2+}$ homeostasis by modulating expression of PTH and stanniocalcin. Endocrinology 155 56-67. (doi:10.1210/en.2013-1608)

Lu M, Wagner GF \& Renfro JL 1994 Stanniocalcin stimulates phosphate reabsorption by flounder renal proximal tubule in primary culture. American Journal of Physiology 267 R1356-R1362.

Luo CW, Pisarska MD \& Hsueh AJ 2005 Identification of a stanniocalcin paralog, stanniocalcin-2, in fish and the paracrine actions of stanniocalcin-2 in the mammalian ovary. Endocrinology 146 469-476. (doi:10.1210/en.2004-1197)

Ma SW \& Copp DH 1978 Purification, properties and action of a glycopeptide from the corpuscles of Stannius which affect calcium metabolism in the teleost. In Comparative Endocrinology pp 283-286. Eds PJ Gaillard \& HD Boeh, Amsterdam, Elsevier, North Holland.

McCudden CR, James KA, Hasilo C \& Wagner GF 2002 Characterization of mammalian stanniocalcin receptors. Mitochondrial targeting of ligand and receptor for regulation of cellular metabolism. Journal of Biological Chemistry 277 45249-45258. (doi:10.1074/jbc.M205954200)

Olsen HS, Cepeda MA, Zhang QQ, Rosen CA \& Vozzolo BL 1996 Human stanniocalcin: a possible hormonal regulator of mineral metabolism. PNAS 93 1792-1796. (doi:10.1073/pnas.93.5.1792)

Paciga M, Hirvi ER, James K \& Wagner GF 2005 Characterization of big stanniocalcin variants in mammalian adipocytes and adrenocortical cells. American Journal of Physiology. Endocrinology and Metabolism 289 E197-E205. (doi:10.1152/ajpendo.00581.2004)

Perry SF 1997 The chloride cell: structure and function in the gills of freshwater fishes. Annual Review of Physiology 59 325-347. (doi:10.1146/ annurev.physiol.59.1.325)

Pfaffl MW 2001 A new mathematical model for relative quantification in real-time RT-PCR. Nucleic Acids Research 29 e45. (doi:10.1093/nar/ 29.9.e45)

Shin J \& Sohn YC 2009 cDNA cloning of Japanese flounder stanniocalcin 2 and its mRNA expression in a variety of tissues. Comparative Biochemistry and Physiology. Part A, Molecular \& Integrative Physiology 153 24-29. (doi:10.1016/j.cbpa.2008.11.014)

Takei Y, Hiroi J, Takahashi H \& Sakamoto T 2014 Diverse mechanisms for body fluid regulation in teleost fishes. American Journal of Physiology. Regulatory, Integrative and Comparative Physiology 307 R778-R792. (doi:10.1152/ajpregu.00104.2014)

Thastrup O, Cullen PJ, Drobak BK, Hanley MR \& Dawson AP 1990 Thapsigargin, a tumor promoter, discharges intracellular $\mathrm{Ca}^{2+}$ stores by specific inhibition of the endoplasmic reticulum $\mathrm{Ca}^{2+}$-ATPase. PNAS 87 2466-2470. (doi:10.1073/pnas.87.7.2466)

Tse WK, Au DW \& Wong CK 2006 Characterization of ion channel and transporter mRNA expressions in isolated gill chloride and pavement cells of seawater acclimating eels. Biochemical and Biophysical Research Communications 346 1181-1190. (doi:10.1016/j.bbrc.2006.06.028)

Tseng DY, Chou MY, Tseng YC, Hsiao CD, Huang CJ, Kaneko T \& Hwang PP 2009 Effects of stanniocalcin 1 on calcium uptake in zebrafish (Danio rerio) embryo. American Journal of Physiology. Regulatory, Integrative and Comparative Physiology 296 R549-R557. (doi:10.1152/ajpregu.90742. 2008)

Wagner GF, Hampong M, Park CM \& Copp DH 1986 Purification, characterization, and bioassay of teleocalcin, a glycoprotein from salmon corpuscles of Stannius. General and Comparative Endocrinology 63 481-491. (doi:10.1016/0016-6480(86)90149-8)

Wagner GF, Fargher RC, Milliken C, McKeown BA \& Copp DH 1993 The gill calcium transport cycle in rainbow trout is correlated with plasma levels of bioactive, not immunoreactive, stanniocalcin. Molecular and Cellular Endocrinology 93 185-191. (doi:10.1016/03037207(93)90122-Z)

Wong CK \& Chan DK 1999a Chloride cell subtypes in the gill epithelium of Japanese eel Anguilla japonica. American Journal of Physiology 277 R517-R522.

Wong CK \& Chan DK 1999b Isolation of viable cell types from the gill epithelium of Japanese eel Anguilla japonica. American Journal of Physiology 276 R363-R372.

Wu S, Yoshiko Y \& De Luca F 2006 Stanniocalcin 1 acts as a paracrine regulator of growth plate chondrogenesis. Journal of Biological Chemistry 281 5120-5127. (doi:10.1074/jbc.M506667200)

Zeiger W, Ito D, Swetlik C, Oh-hora M, Villereal ML \& Thinakaran G 2011 Stanniocalcin 2 is a negative modulator of store-operated calcium entry. Molecular and Cellular Biology 31 3710-3722. (doi:10.1128/MCB. 05140-11)

Received in final form 4 March 2015

Accepted 27 March 2015 http://jme.endocrinology-journals.org

DOI: 10.1530/JME-14-0320
(C) 2015 Society for Endocrinology Printed in Great Britain
Published by Bioscientifica Ltd. 